\title{
Viewpoint
}

\section{Clinical trials: why not do them properly?}

Clinicians who embark on clinical trials take on a commitment over and above the care of individual patients in their charge and hope to gather knowledge which will help both their patients collectively and society in general. Most are aware that such trials will involve them in considerable time and effort in preparation, execution, and analysis and their patients in extra visits, blood tests, and other assessments. It seems to me, however, that many clinicians undertaking trials are unaware that the procedures necessary when managing patients in groups are quite different from those appropriate to individual patients. I believe that a failure to appreciate this underlies many of the serious flaws in published trials.

Such flaws are not merely questions of minor statistical inference to interpretation. They are often major errors in basic trial design or nonsensical manoeuvres in analysis. The result is usually to invalidate the conclusions of the trial (sometimes even before they are read) and thus to waste the time, effort, and energy of those who took part in it. When published, such trials serve to swell the medical literature with information which is at best uninformative and at worst misleading and make it harder to separate the wheat from the chaff.

There are 3 major recurring flaws in trials published in the British rheumatology journals over the last 4 years. While their frequency varies from year to year and journal to journal (in last year's Annals I could find only a single offender), at least one flaw occurs in about $70 \%$ of the papers taken together.

Flaw 1. Time after time investigators set out to answer a question such as, Is treatment $A$ better than treatment $B$ ? and recruit insufficient entrants to their trial to provide the answer (even if one treatment is twice as effective as the other). Because of the inherent variability between individuals and their responses to therapy, patients can be usefully assessed in groups only if these groups are sufficiently large. It is not difficult to calculate how many trial entrants are required, ${ }^{1}$ but the answer may be in hundreds rather than tens for many treatment trials. The question arises whether it is not immoral to ask patients to take part in a trial one knows (or ought to know) is unlikely to produce a useful result.

Flaw 2. Claiming that a failure to demonstrate a difference between 2 treatments indicates that these treatments are equally efficacious is both incorrect and misleading. Similarity has to be proved, just as difference has to be proved, and this requires not only the appropriate statistical analysis but also a large number of patients-much larger than those included in most published trials.

Flaw 3 A third area of concern is the mysterious loss of patients from many published trials. Patients withdrawn from treatment regimens are frequently merely omitted from the figures or reported only in the incidence of side effects. They are rarely included in the overall analysis of efficacy. This raises an important and fundamental issue. It is possible to consider the efficacy of a treatment in 2 different ways-its efficacy for those who can tolerate it and its efficacy for patients in general. Omitting the withdrawals from the analysis of results allows only the first assessment. This approach may (or may not) be appropriate in investigating the pharmacological properties of a particular compound, but it tells us little about the risks and benefits we have to weigh up when deciding whether to treat our next patient with the drug. Even when withdrawals are subject to further treatment they should still be included (within the original allocation groups) in the analysis of the outcomes of the initial treatment policies. Such policies include, either explicitly, or more frequently implicitly, alternative courses of action should treatment fail, and these are in both cases part of the therapy under trial. No valid conclusions relating to the practical management of patients can be drawn from an analysis in which any significant number of patients have been removed, for whatever reason, from the treatment groups under consideration. (Some investigators take this error one stage further and actually transfer patients from one treatment group to another.)

Are there any guidelines the trialist can follow to help avoid some of these pitfalls?

(1) Calculate how many patients are likely to be 
required in advance of starting the trial. ${ }^{1}$ It will usually be more than expected.

(2) In view of the work involved in recruiting these extra patients: (a) Make sure the question asked is worth the effort. (b) Minimise the data collected on each patient. (c) Consider collaboration with other investigators.

(3) Remember that patients who withdraw from a particular treatment regimen do not withdraw from the trial.

(4) Always include an analysis of the effects of the initial treatment policies on all patients to enable clinicians to decide if the results are relevant to their own practice.

There is considerable pressure to read or publish papers, a factor which may account for not only some of these failings but also for the increasing reporting of unfinished 'trials in progress,' which by their very nature cannot provide any answers. The responsibility for counteracting this pressure must lie with many people, including journal editors, programme organisers at scientific meetings, trial supervisors, and individual clinicians inviting their patients to participate in trials. Statisticians too must bear some of the burden and, as in other fields such as cancer therapy, leave what often seems the ivory tower of the 'department of numbers' and tackle the problem of real, live, difficult-to-organise doctors and their patients. Proper trials take more time, more patients, more doctors, and more journal space. All these would be available if we abandoned the distractions of basically unproductive endeavours.

ARC Research Fellow, JOHN R KIRWAN

Bone \& Joint Research Unit, The London Hospital, London, E1.

\section{Reference}

1 Altman D G. Statistic and ethics in medical research III. How large a sample? Brit Med J 1980; 281: 1336-8.

\section{Notes}

\section{Congress of Rheumatology}

The Tenth European Congress of Rheumatology will be held in Moscow, on 26 June-2 July 1983. The key-note subject will be 'Rheumatic disease related to sex and age.' Principal topics include: age and sex problems in rheumatic disease; fundamental research in rheumatology; recent achievements in inflammatory rheumatic disease research; recent achievements in metabolic and degenerative rheumatic disease research; latest advances in treatment of rheumatic disease; Medico-social and education problems in rheumatology. The final date for preliminary registration is 20 April 1983, and for receipt of abstracts 15 January 1983. The USSR Company for Foreign Travel 'Intourist' is the official travel agent for the congress. Further details from the Organising Committee, Institute of Rheumatology, USSR Acad. Med. Sci., 25 Petrovka str, 103031, Moscow, USSR.

\section{Anglo-US travel fellowships in rheumatology}

The Arthritis and Rheumatism Council and the American Rheumatism Association announce the inauguration of a travelling fellowship scheme for promising young clinicians and scientists dedicated to careers in investigative rheumatology. In alternate years 4 US or UK fellows will spend one month visiting transatlantic rheumatology centres and will attend the national meeting of the Heberden Society or the ARA. The first group of US fellows will visit the UK in November 1983. Applications from UK citizens under the age of $\mathbf{4 0}$ for fellowships to visit rheumatology centres in the US and attend the annual meeting of the ARA in June 1984 will be considered by the ARC in October 1983. Further details from Miss Rachel Inglis, Deputy Secretary of the Arthritis and Rheumatism Council, 41 Eagle Street, London WC1R 4AR. 